\title{
PLASMA RICO EM FIBRINA COMO CARREADOR DE BIOMATERIAL PARA RECONSTRUÇÃO ALVEOLAR APÓS EXODONTIA: RELATO DE CASO
}

\section{Caio Botelho Vieira de Lacerda}

Graduado em Odontologia pela Universidade Federal Fluminense - UFF, Niterói / RJ, Brasil.

\section{Fernanda Britto de Melo Silva}

Residente de Cirurgia Oral e Maxilofacial do Hospital Federal dos Servidores do Estado do Rio de Janeiro - HFSE, Rio de Janeiro / RJ, Brasil. e da Universidade Federal Fluminense UFF, Niterói / RJ, Brasil.

\section{Josiane Costa Rodrigues de Sá}

Professora da disciplina de Diagnóstico Bucal da Faculdade de Odontologia da Universidade Federal Fluminense, Niterói / RJ, Brasil.

\section{Rafael Seabra Louro}

Professor da disciplina de Cirurgia Bucal da Universidade Federal Fluminense , Niterói / RJ, Brasil.

\section{Rodrigo Figueiredo de Brito Resende}

Professor da disciplina de Cirurgia Bucal da Universidade Federal Fluminense , Niterói / RJ, Brasil.

Instituição na qual o trabalho foi realizado: Faculdade de Odontologia da Universidade Federal Fluminense Niterói/RJ

Categoria: Relato de caso

\section{Informações do autor principal:}

Caio Botelho Vieira de Lacerda

Rua Garibaldi, 193

Tijuca- Rio de Janeiro- RJ, Brasil.

CEP: 20511330

Email: caiolacerda2@ hotmail.com

Telefone: +5521993291515 


\title{
Resumo
}

A reabsorção óssea alveolar pós-exodontia é um dificultador para tratamentos odontológicos posteriores como implantes dentários ou ortodontia. Por essa razão, procedimentos de preservação do osso alveolar se fazem necessários para muitos pacientes. O Plasma rico em Fibrina (PRF) é um biomaterial autólogo, de baixo custo e fácil obtenção e que representa a segunda geração dos chamados agregados plaquetários. Trata-se de uma membrana de fibrina autógena, rica em leucócitos, plaquetas e fatores de crescimento, obtida através do sangue do paciente que passa por um processo de centrifugação. Esse material apresenta diversas utilidades para odontologia e sua forma injetável, o i-PRF tem se apresentado como uma boa alternativa para procedimentos de preservação óssea alveolar pós-extração dentária, em especial, quando utilizado em conjunto com enxertos ósseos particulados. O objetivo do presente trabalho é relatar um caso clínico do paciente L.S.L.P., sexo masculino, 20 anos de idade, que compareceu a clínica de siso incluso da Faculdade de Odontologia da UFF com solicitação do Departamento de Ortodontia para exodontia dos elementos 37 e 47 (segundos molares inferiores) para posterior movimentação dos terceiros molares inferiores para oclusão. Neste caso foi utilizado i-PRF como carreador de biomaterial para preservação e neoformação óssea em alvéolo dentário pós-exodontia. O procedimento cirúrgico foi realizado sob anestesia local em ambiente ambulatorial, sem intercorrências e o mesmo segue em controle pós-operatório com cerca de 1 mês, com boa evolução.

Palavras-chave: fibrina rica em plaquetas; ortodontia; cirurgia oral e maxilofacial.

\begin{abstract}
Post-extraction alveolar bone resorption is a barrier to subsequent dental treatments such as dental implants or orthodontics. For this reason, alveolar bone preservation procedures are required for many patients. Fibrin-rich Plasma (PRF) is a low cost, easily obtainable autologous biomaterial representing the second generation of so-called platelet aggregates. It is an autogenous fibrin membrane, rich in leukocytes, platelets and growth factors, obtained through the patient's blood that goes through a centrifugation process. This material has several uses for dentistry and its injectable form, i-PRF, has been presented as a good REVISTA FLUMINENSE DE ODONTOLOGIA - ANO XXVI - No 53 - Janeiro / Julho 2020
\end{abstract}


alternative for post-extraction alveolar bone preservation procedures, especially when used in conjunction with particulate bone grafts. The aim of the present study is to report a case of a 20-year-old male LSLP patient who attended the Fluminense Federal University Dental School with request from the Department of Orthodontics for extraction of elements 37 and 47 (lower second molars) for posterior movement of the lower third molars for occlusion. In this case, i-PRF was used as a biomaterial carrier for bone preservation and neoformation in a dental socket after extraction. The surgical procedure was performed under local anesthesia in an outpatient setting, uneventful and the same follows in postoperative control with about 1 month, with good evolution.

Keywords: platelet-rich fibrin; orthodontics; oral and maxillofacial surgery. 
COPYRIGHT @ 2020 INTERNATIONAL JOURNAL OF SCIENCE DENTISTRY | AVAILABLE ONLINE http://www.periodicos.uff.br/index

\section{Introdução}

A exodontia é um procedimento comum na rotina odontológica, sendo opção de tratamento para doenças periodontais, infecções dentárias, ganho de espaço para tratamento ortodôntico e fraturas dentais. A cicatrização fisiológica do alvéolo pós-extração envolve complexos processos de migração e maturação de células ósseas que levam a reabsorção e a, consequente, perda de volume desse tecido na região (ALZAHRANI AA, MURRIKY A, ET AL. 2017). Estudos mostram que há significativa perda óssea alveolar tridimensional após a extração dentária. Essa perda dificulta os tratamentos para recuperação do elemento dentário, principalmente os de implante dentário e ortodontia. (ALZAHRANI AA, MURRIKY A, ET AL. 2017; PAN J, XU Q, ET AL. 2019)

Nesse sentido, fazem-se necessários procedimentos cirúrgicos para preservação do alvéolo. Os métodos envolvem o uso de enxertos e fatores de crescimento com ou sem membranas reabsorvíveis para recobrimento. O objetivo desses tratamentos é a preservação dos tecidos moles e duros do alvéolo pós-exodontia (PAN J, XU Q, ET AL. 2019).

A preservação do alvéolo dentário com uso de biomateriais é possível com o uso dos agregados plaquetários como plasma rico em plaquetas (PRP) e o plasma rico em fibrina (PRF) (ALZAHRANI AA, MURRIKY A, ET AL. 2017). O PRF é a segunda geração de agregados plaquetários, desenvolvido por Choukroun et al. em 2001 consiste em uma matriz de fibrina polimerizada em uma estrutura tetramolecular que incorpora plaquetas, leucócitos, citocinas, fatores de crescimento e células tronco circulantes (DE ANDRADE LS, LEITE LP, ET AL. 2018)

Existem diferentes protocolos de obtenção e utilização do PRF, uma delas é o PRF injetável ou i-PRF. Após sua obtenção, ele pode ser utilizado em sua forma liquida ou aglutinado a enxertos ósseos, como a hidroxiapatita, formando um bife para enxertia óssea (MOURÃO CFAB, VALIENSE H, ET AL. 2015). Com o processo de coagulação, o i-PRF forma uma consistência de gel, segurando consigo o enxerto ósseo. Além disso, a liberação de fatores de crescimento é benéfica ao enxerto, proporcionando uma cicatrização óssea satisfatório, além de favorecer uma melhora do reparo tecidual (ATALAY B, DOGANAY O. 2018).

REVISTA FLUMINENSE DE ODONTOLOGIA - ANO XXVI - No 53 - Janeiro / Julho 2020 
O presente trabalho tem como objetivo relatar um caso de utilização do i-PRF como carreador de biomaterial com objetivo de preservação de alvéolo dentário após exodontia, possibilitando tratamento ortodôntico futuro.

\section{Considerações éticas}

Os procedimentos empregados neste trabalho seguiram os padrões éticos propostos pela Declaração de Helsinque de 1975, revisada em 2000. O paciente foi tratado na Faculdade de Odontologia da Universidade Federal Fluminense através da Clínica de dentes inclusos com os termos, de consentimento livre e esclarecido e de uso de imagens e dados para publicação científica, assinados.

O estudo foi escrito seguindo as Diretrizes do Relatório de Caso Clínico (CARE, www.care-statement.org).

\section{Relato de Caso}

Paciente L.S.L.P., sexo masculino, 20 anos de idade, compareceu a clínica de siso incluso da Faculdade de Odontologia da Universidade Federal Fluminense, com encaminhamento do Departamento de Ortodontia solicitando exodontia dos elementos 37 e 47 (segundos molares inferiores) para posterior movimentação dos terceiros molares inferiores para oclusão.

Ao exame clínico o paciente apresentava o primeiro e o terceiro molar inferior em oclusão, impactando assim o segundo molar, que se apresentava incluso. O paciente já havia sido submetido a exodontia do elemento 37 em um procedimento prévio.

No exame de imagem, através de uma radiografia panorâmica de face, evidenciava-se o segundo molar em posição mesio-angulado e proximidade com a basilar da mandíbula (Figuras 1A).

Inicialmente, foram coletados cerca de $18 \mathrm{ml}$ de sangue do paciente, em 2 tubos de $9 \mathrm{ml}$ cada (tubos sem adição de aditivos), utilizando-se o sistema fechado à vácuo de coleta. Esse material foi centrifugado por 12 minutos a 2700rpm para obtenção do i-PRF.

REVISTA FLUMINENSE DE ODONTOLOGIA - ANO XXVI - № 53 - Janeiro / Julho 2020 
Em seguida, foi realizada a exodontia do elemento $47 \mathrm{em}$ ambiente ambulatorial sob anestesia local com Lidocaína 2\% e Epinefrina 1:100.000, através das técnicas de bloqueio dos nervos alveolar inferior, lingual e bucal do lado esquerdo. Foi aberto retalho muco periósteo total em envelope na região utilizando-se lâmina de bisturi 15. Logo após, foi realizada osteotomia e odontosecção cuidadosa com a finalidade de preservar os elementos dentários adjacentes (Figuras 1B e 1C).

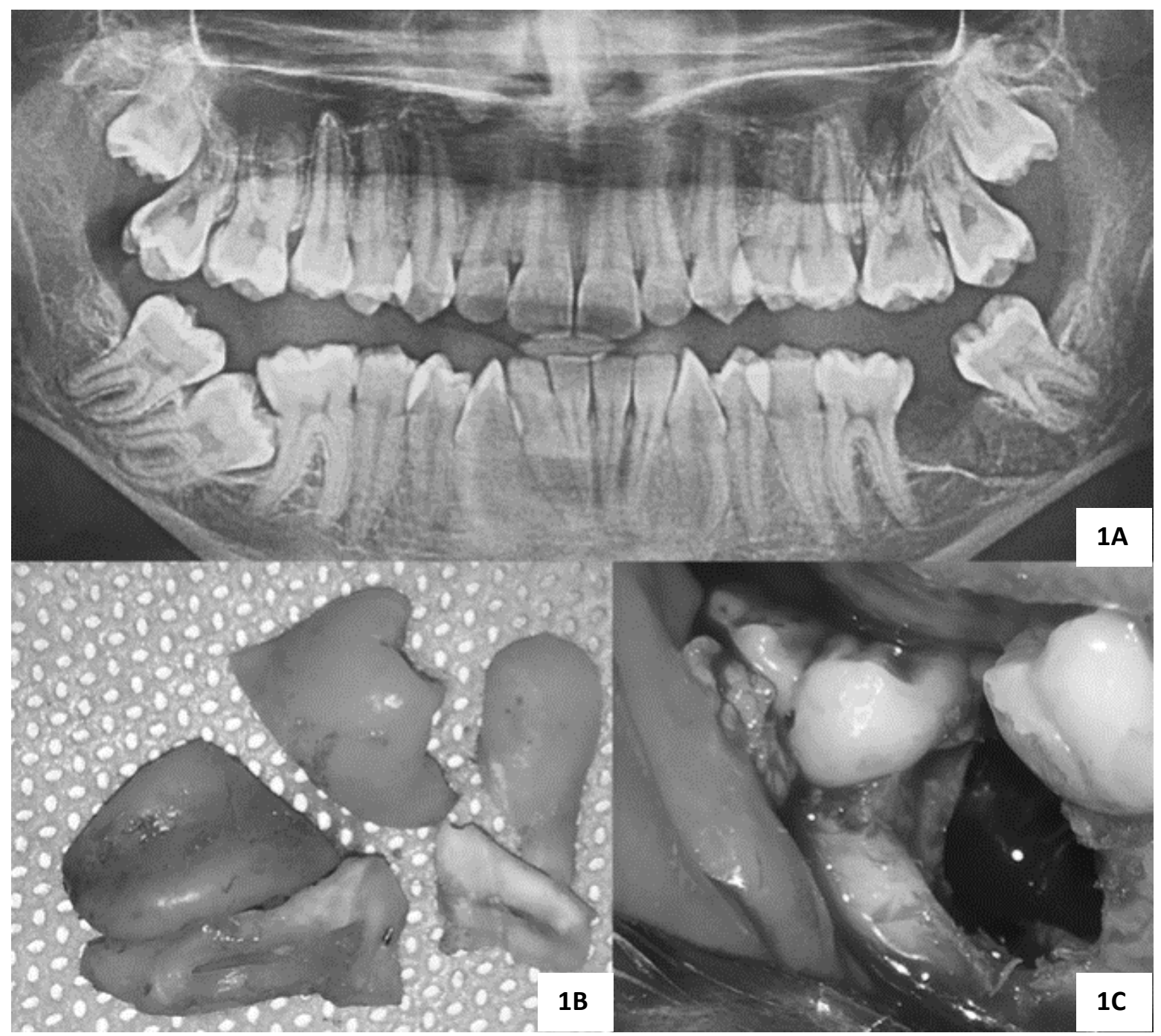

1. A) Radiografia Panorâmica de Face; B) Odontosecção realizada para exodontia do elemento dentário; C) Alvéolo contendo coágulo. 
COPYRIGHT @ 2020 INTERNATIONAL JOURNAL OF SCIENCE DENTISTRY | AVAILABLE ONLINE http://www.periodicos.uff.br/index

Posteriormente, coletou-se dos tubos o i-PRF utilizando-se uma pipeta, o qual foi disposto em uma cuba metálica e aglutinado a um material de enxerto substituto ósseo sintético de grânulos de hidroxiapatita (Figuras 2A e 2C). O tudo de coleta utilizado não continha sílica (ativador de coágulo) em sua composição, o que permite a obtenção do PRF em fase líquida (Figuras 2B).

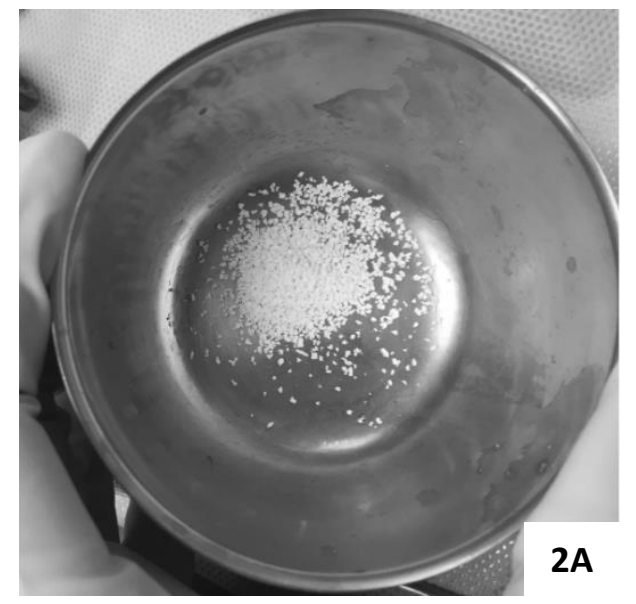

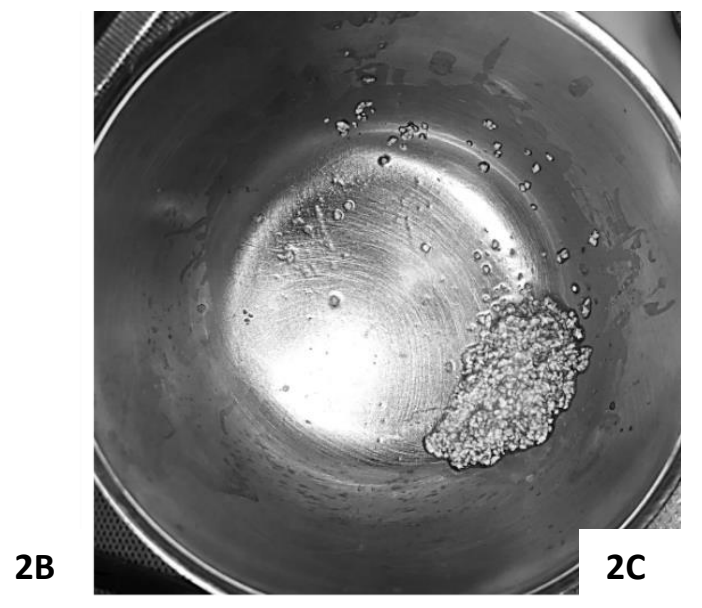

2. A) Membranas obtidas através do sangue centrifugado; B) Tubo Branco utilizado na coleta sem ativador de coágulo; C) Biomaterial aglutinado ao I- PRF.

O material obtido foi utilizado para preencher o alvéolo pós-exodontia (Figuras 3A e 3B) e então, foi realizada a síntese tecidual utilizando-se fio Vicryl 3.0. 


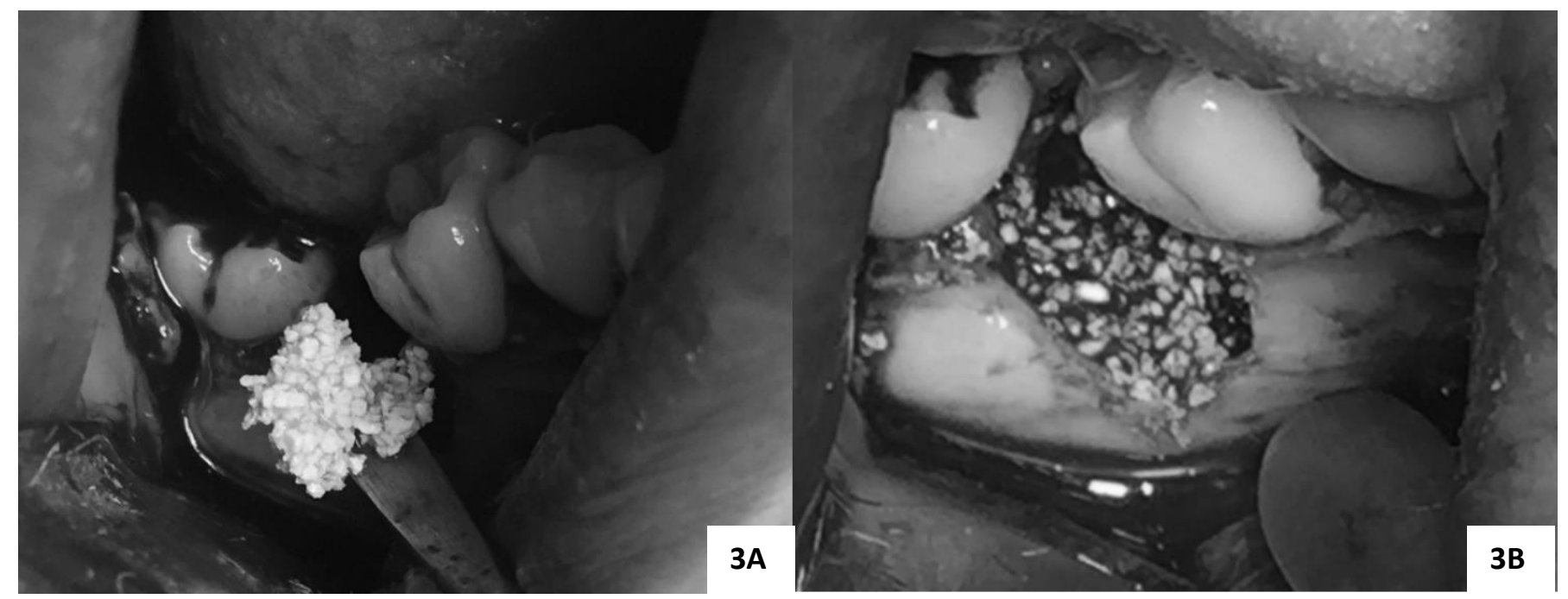

3. A) Grânulos de biomaterial substituto ósseo aglutinado com o I-PRF sendo inserido no alvéolo; B) Biomaterial acomodado no alvéolo dentário.

\section{Discussão}

O PRF foi utilizado pela primeira vez em 2001 por Choukroun et al., na França, especificamente em cirurgia oral e maxilofacial e é considerado a segunda geração de agregados plaquetários. Esse material consiste em uma matriz autóloga de fibrina rica em plaquetas e leucócitos, composta por uma estrutura tetra molecular que funciona como uma plataforma biodegradável que favorece o desenvolvimento da microvascularização e é capaz de guiar a migração de células epiteliais para a superfície. (BORIE E, OLIVÍ DG, ET AL. 2015)

Além disso, PRF serve como veículo para células envolvidas na regeneração tecidual e promove uma contínua liberação de fatores de crescimento, estimulando um ambiente propicio para a cicatrização de feridas. Apresenta uma estrutura semelhante à de um coágulo sanguíneo, no entanto, é considerado mais homogêneo e estável, sendo mais fácil sua manipulação e posicionamento no local indicado. (TEMMERMAN A, VANDESSEL J, ET AL. 2016; CHHABRA P, CHHABRA P, ET AL. 2019)

REVISTA FLUMINENSE DE ODONTOLOGIA - ANO XXVI - No 53 - Janeiro / Julho 2020 
Em procedimentos cirúrgicos, o PRF pode servir como membrana para regeneração óssea guiada, prevenindo a migração de células indesejadas para o defeito ósseo e promovendo a atração de células osteogênicas e angiogênicas, que irão favorecer a mineralização do coágulo sanguíneo no local. As membranas de PRF ajudam na cicatrização de feridas, protegendo o sitio cirúrgico e promovendo reparo do tecido mole, e quando combinadas com enxertos ósseos, atuam como um carreador biológico, que atrai células tronco, células osteoprogenitoras e favorece a neo-angiogenese. (BORIE E, OLIVÍ DG, ET AL. 2015)

A obtenção do i-PRF só é possível com a utilização de tubos sem aditivos para a coleta do sangue. Além disso, os tubos usados nessa técnica não contêm sílica (ativador de coágulo) na composição de suas paredes, ao contrário dos tubos utilizados na preparação da membrana de PRF. Enquanto no tubo com anticoagulantes é formado um material trifásico de onde se retira a membrana de PRF, no tubo sem aditivos forma-se um material liquido monofásico, o i-PRF. A possibilidade da aglutinação do i-PRF com biomateriais para enxertia óssea cria uma alternativa ao PRP como agregado plaquetário para regeneração óssea. O PRP é utilizado em procedimentos regenerativos devido a possibilidade de otimizar a neoformação óssea (MOURÃO CFAB, VALIENSE H, ET AL. 2015).

Devido a sua forma liquida, o i-PRF funciona muito bem como carreador para biomateriais, oferecendo a possibilidade de aglutinação a materiais de enxerto ósseo, como no presente estudo, possibilitando uma melhor acomodação do enxerto no sitio receptor. Dessa forma, atua como um conector biológico entre diferentes elementos do enxerto e serve como uma matriz que facilita a formação de novo tecido ósseo no defeito (MOURÃO CFAB, VALIENSE H, ET AL. 2015; ATALAY B, DOGANAY O. 2018)

Algumas vantagens do uso do i-PRF são: a facilidade e o baixo custo de sua obtenção; rápido tempo de preparo; o fato de ser um material autólogo (sem risco de reação imunológica); pode ser aglutinado a enxertos ósseos, facilitando sua manipulação e posicionamento no sitio cirúrgico, além de oferecer fatores de crescimento que podem ajudar na regeneração tecidual.

REVISTA FLUMINENSE DE ODONTOLOGIA - ANO XXVI - No 53 - Janeiro / Julho 2020 


\section{Conclusão}

O I- PRF obtido através do sangue do próprio paciente mostrou-se uma excelente alternativa quando utilizado como carreador de um biomaterial substituto ósseo, favorecendo o reparo ósseo, com o objetivo de permitir tratamento ortodôntico futuro. Ainda, apresenta baixo custo e facilidade de obtenção. Neste sentindo, foi possível observar que a associação deste concentrado com o enxerto ósseo escolhido favoreceu a inserção do biomaterial no alvéolo dentário, permitindo que o mesmo se acomodasse de forma satisfatória.

\section{Referências Bibliográficas:}

1. Alzahrani AA, Murriky A, Shafik S. Influence of platelet rich fibrin on postextraction socket healing: a clinical and radiographic study. Saudi Dent J. 2017 Oct; 29(4):149-155.

2. Pan J, Xu Q, Hou J, Wu Y, Liu Y, Li R, et al. Effect of platelet rich fibrin on alveolar ridge preservation: A systematic review. J Am Dent Assoc. 2019 Sep; 150(9):766-778.

3. De Andrade LS, Leite L P, De Melo Silva FB, De Brito Resende RF, Guedes De Uzeda MJ. The use of platelet-rich fibrin concentrate in tissue healing and regeneration in dentistry. Int J Growth Factors Stem Cells Dent 2018; 1:23-6.

4. Mourão CFAB, Valiense H, Melo ER, Mourão NBMF, Maia MDC. Obtention of injectable platelets rich-fibrin (i-PRF) and its polymerization with bone graft: technical note. Rev Col Bras Cir. 2015; 42(6):421-423

5. Belir Atalay and Ozge Doganay (November 5th 2018). The Use of Platelet-Rich Fibrin in Bone Grafting, Bone Grafting - Recent Advances with Special References to Cranio-Maxillofacial Surgery, Raja Kummoona, IntechOpen, DOI: 10.5772/intechopen.79825. Available from: https://www.intechopen.com/books/bone-grafting-recent-advances-with-specialreferences-to-cranio-maxillofacial-surgery/the-use-of-platelet-rich-fibrin-in-bonegrafting 
6. Borie E, Oliví DG, Orsi IA, Garlet K, Weber B, Beltrán V, et al. Platelet-rich fibrin application in dentistry: a literature review. Int J Clin Exp Med. 2015; 8(5):79227929

7. Temmerman A, Vandessel J, Castro A, Jacobs R, Teughels W, Pinto N, et al. The use of leucocyte and platelet-rich fibrina in socket management and ridge preservation: a split mouth, randomized, controlled clinical trial. J Clin Periodontol. 2016; 43:990-99

8. Chhabra P, Chhabra P, Sharma K. Platelet rich fibrin - it's structural design and composition. International Journal of Oral Health Dentistry. 2019 Apr; 5(2):81-84 